\title{
Antinuclear antibodies in patients with scleroderma (systemic sclerosis) and in their blood relatives and spouses
}

\author{
A J Barnett, L J McNeilage
}

\begin{abstract}
Objective-To test the postulate that there is a higher prevalence of antinuclear antibodies (ANAs) in serum samples from blood relatives and from spouses of patients with scleroderma than in control samples, and that this provides evidence for both genetic and environmental factors influencing autoimmunity in scleroderma. Method-Testing for ANAs was performed on 58 patients with scleroderma, 30 of their spouses, 74 first degree relatives, and 66 control subjects broadly age matched to the patients, their spouses, and about half of the relatives (siblings and parents).

Results-On the basis of an ANA titre of $>40$ as positive, $12(18 \%)$ of the controls, $55(95 \%)$ of the patients, one $(3 \%)$ of the spouses and five $(7 \%)$ of the relatives would be classified as positive. Thirty seven $(64 \%)$ of the patients had defined specificities (ACA, Scl 70, U1 (RNP)) but none of the controls, spouses, or relatives had antibodies of these specificities.

Conclusion-These findings give no support to the postulate that environmental or genetic factors contribute to the ANAs in scleroderma.
\end{abstract}

(Ann Rheum Dis 1993; 52: 365-368)

Scleroderma (systemic sclerosis) is an uncommon condition of obscure aetiology characterised clinically by symmetrical stiffness of the skin, Raynaud's phenomenon, and involvement of various internal organs. Over $90 \%$ of patients with scleroderma have antinuclear antibodies (ANAs) of various types in their serum ${ }^{1}$ and, although it is not clear whether their presence is an initial feature of the disease or whether they develop secondarily, certain specificities, namely anticentromere, antitopoisomerase ( $\mathrm{Scl} 70)$, and antinucleolar antibodies are characteristic of scleroderma. $^{2}$ Rare examples of a familial occurrence of the condition have been reported $^{3-7}$ and there have been reports of HLA associations, ${ }^{8-14}$ suggesting a genetic predisposition. The development of scleroderma or scleroderma-like conditions, however, in association with various toxic agents including silica, ${ }^{15-17}$ silicon, ${ }^{18}$ vinyl chloride, ${ }^{19-21}$ industrial solvents, ${ }^{22-23}$ and rape seed oil, ${ }^{24}$ have suggested the possibility of environmental factors as a cause of the condition.
Maddison et $a l^{25}$ examined the prevalence of ANA in patients with scleroderma, their blood relatives, and spouses. They found a higher prevalence of ANA both in the blood relatives (27\%) and in the spouses (24\%) compared with controls $(8 \%)$ and suggested that these findings support the notion that both genetic and environmental factors influence autoimmunity in scleroderma. The present study was undertaken to investigate this idea in another population of patients with scleroderma.

\section{Patients and methods}

PATIENTS

The patients with scleroderma were under the care of one of us (AJB) or were members of the Scleroderma Foundation of Victoria. They had symmetrical skin stiffness, Raynaud's phenomenon, and some evidence of systemic involvement. They were classified according to a scheme previously described ${ }^{26}$ based on the extent of the skin stiffness; type 1 disease indicates involvement of the skin of the fingers only, type 2 involvement of the arms and face but excluding the trunk, and type 3 extensive involvement including the trunk. The patients were asked to bring one or more first degree blood relatives (offspring, parents, siblings) and, if possible, a spouse. The relatives and spouses were all interviewed with the aim of detecting any evidence of scleroderma or connective tissue disease and their hands and face were inspected. Control serum samples (total 65) were obtained from patients in hospital (31) and a healthy population (34) broadly matched with the scleroderma patients by age. The healthy controls were obtained partly from volunteer receptionists in doctors' rooms and partly from volunteer relatives of patients in a repatriation hospital. They were questioned to exclude the presence of any autoimmune disease. The hospital controls were obtained from patients attending a haematology clinic for routine blood tests. Their notes were inspected to exclude any subjects with autoimmune disease such as diabetes or thyroid disease, infections, or autoimmune cytopenias including thrombocytopenia. Only two patients were blood relatives (first cousins). About one quarter of the relatives were siblings, one quarter parents, and one half children of the patients. Five only had experienced Raynaud's phenomenon; one of these had nailfold capillary changes 
suggestive of scleroderma. None had the skin changes characteristic of scleroderma. Several complained of joint aches and pains but these were no more frequent than in the general population and none had features of connective tissue disease. Among the spouses, husbands predominated over wives in the ratio of about 3 to 1 , the reverse of the sex incidence in patients with scleroderma. None had Raynaud's phenomenon or features of connective tissue disease. The table shows the age distribution and sex of the subjects and the type of the scleroderma.

\section{METHODS}

Blood samples were taken by venepuncture, centrifuged, and the serum samples coded and frozen on the same day. The coded samples were stored at $-20^{\circ} \mathrm{C}$ until tested. The ANA tests were performed without knowledge of clinical data or subject group.

Autoantibodies to nuclear and cytoplasmic antigens were detected by immunofluorescence with the human epithelial cell line HEp2 (Immunoconcepts, Sacramento, California). Serum was titrated in quadrupling dilutions from $1 / 40$ to $1 / 640$. The staining pattern was determined for all positive samples. Those positive by immunofluorescence were tested for antibodies to the extractable nuclear antigens topisomerase 1 (Scl 70), U1 (RNP), Sm, Ro (SS-A), La (SS-B), Jo-1, Mi 2, and $\mathrm{Ku}$ by counterimmunoelectrophoresis (CIEP) with rabbit thymus (Pel Freeze Biologicals, Rogers, Arkansas) and human spleen as sources of antigens and appropriate reference serum samples for specificity.

\section{Results}

The table shows that $39 \%$ of the controls were negative for ANAs, and $42 \%$ had ANAs of low titre (40) and $18 \%$ (all but two in the $60-89$ age group) had ANAs of $>160$. By contrast, most $(70 \%)$ of the spouses were negative for ANAs, with $27 \%$ having an ANA titre of 40 and only $3 \%$ (one patient) with a higher titre (160). The patterns of ANAs detected in the controls, spouses, and first degree relatives were speckled, nucleolar, and homogeneous. In general the first degree relatives resembled the spouses: $65 \%$ were ANA negative, $28 \%$ had ANAs of low titre (40) and 7\% had ANAs of titre 160. All 58 patients were positive for ANAs with most $(95 \%)$ having a titre of $>160$, and only $5 \%$ a titre of 40 . Anticentromere antibodies (ACAs) were detected in $48 \%$ of the patients, antitopoisomerase 1 (Scl 70) in $14 \%$, and anti-U1 (RNP) in $2 \%$. None of the controls, spouses, or first degree relatives had ACA, antitopoisomerase 1, or anti-U1 (RNP) antibodies.

\section{Discussion}

The data showed that the serum samples of our control subjects had a high prevalence of positive ANAs, particularly at the low titre of 40 , suggesting that positivity at this titre is not clinically significant (figure). As would be expected the patients showed a high prevalence of positive ANAs, particularly at the higher titres and $95 \%$ were positive at a titre of $>160$.

By contrast the spouses showed a lower prevalence of positive ANAs than controls at all titres, indicating that the present study provides no evidence that environmental factors contributed to the production of autoantibodies found in patients with scleroderma. This study does not, however, rule out the possibility of a contribution of environmental factors operating in the patients before marriage.

The prevalence of ANAs in the first degree relatives was similar to that in the spouses, again lower than in the control subjects. It is

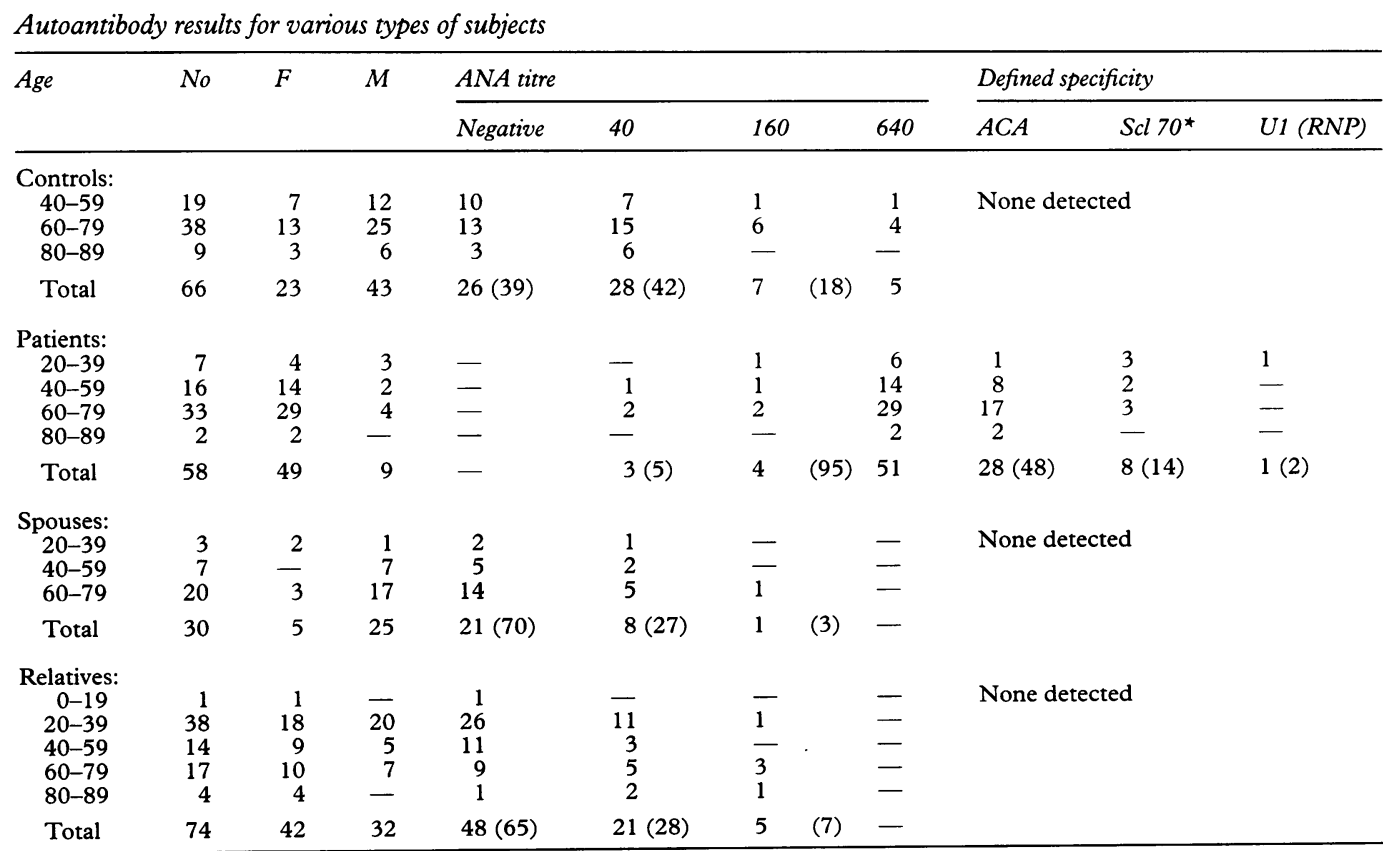




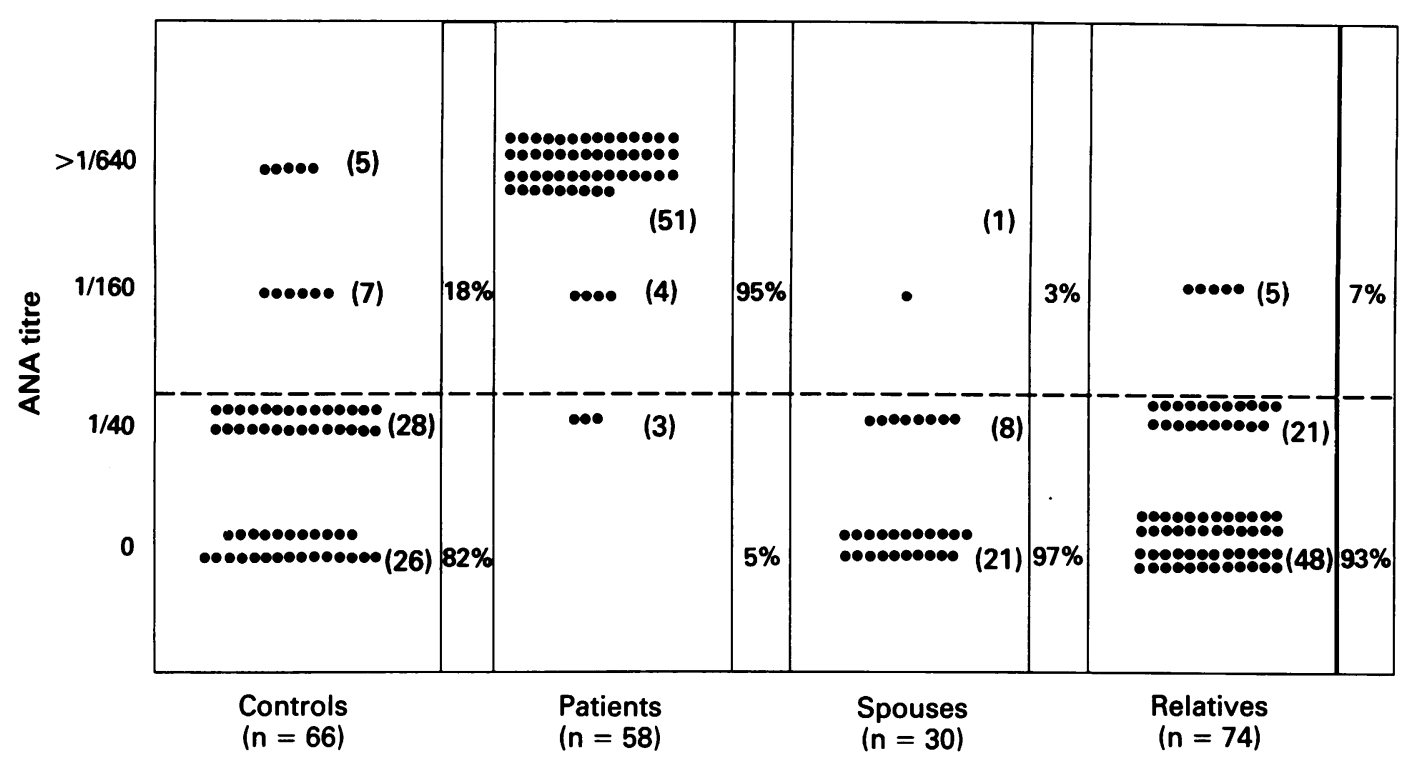

Titres of antinuclear antibodies (ANAs) in control subjects, patients with scleroderma, their spouses, and first degree relatives. The dashed horizontal line indicates suggested level of clinical significance.

relevant that the disease specific autoantibodies (anticentromere and antitopoisomerase I) were confined to the patients with scleroderma and did not occur in any of their family members who would have shared similar HLA and immunoglobulin lines. Unfortunately there are no HLA data in this paper. We can only say that we could find no evidence of a genetic factor in our study. A group of relatives of this size (74) would be expected to contain a significant number with considerable HLA concordance and it would be expected that any important genetic factors would be detected. The relatives fall into two broad groups: a younger group of under 40 years, mainly children of the patients and, a group aged 40 and older, mainly siblings of the patients. The control subjects were broadly age matched with the siblings only. When the data from this group of relatives was compared with the controls, however, the relatives still failed to show any excess of positivity of ANAs. Thus the present study did not find any evidence for genetic influences contributing to autoantibodies in patients with scleroderma.

The control group showed a high prevalence $(60 \%)$ of ANAs compared with other studies ${ }^{27}$ including that of Maddison et al (8\%). ${ }^{25}$ Most $(70 \%)$ of the positive results were of low titre (40). The reason for this high prevalence of ANAs in our controls is not clear. Age may be a factor. All were over 40 and $70 \%$ over 60 . The age of the healthy blood donor controls used by Maddison et $a l^{25}$ was not stated; however it would seem probable that they were a considerably younger group. The prevalence of autoantibodies generally has been found to rise with age (particularly in women), ${ }^{27}$ but it is unlikely that age alone would account for the high prevalence of ANAs in our control subjects. Half of the control subjects were patients in hospital (but without evidence of connective tissue disease) suggesting that ill health may be an influencing factor. The prevalence of ANAs in the patients in hospital was the same as for patients not in hospital.
Other possible variables that are difficult to assess include technique, geography, and race. The technique for detection of ANAs is now standardised worldwide. Our subjects were white people from the city of Melbourne, Australia.

Our thanks are due to the Scleroderma Foundation of Victoria for financial help to buy the reagents used in the tests and to Dr Senga Whittingham of the Walter and Eliza Hall Institute for help in carrying out the tests.

1 Tan E M, Rodnan G P, Garcia I, et al. Diversity of antinuclear antibodies in progressive systemic sclerosis. antinuclear antibodies in progressive systemic sclerosis. Anticentromere antibody and its relationship

2 Tan E M. Antinuclear antibodies: diagnostic markers for autoimmune diseases and probes for cell biology. $A d v$ Immunol 1989; 44: 93-151.

3 McAndrew G M, Barnes E G. Familial scleroderma. Ann Phys Med 1965; 8: 128-31.

4 Burge K M, Perry H O, Stickler C B. Familial scleroderma Arch Dermatol 1969; 99: 681-7.

5 Gray A G, Altman R D. Progressive systemic sclerosis in family: case report of a mother and son and review of the family: case report of a mother and son and

6 Sheldon W B, Lurie D P, Maricg H R, et al. Three siblings with scleroderma (systemic sclerosis) and two with Raynaud's phenomenon from a single kindred. Arthritis Rheum 1981; 24: 668-76.

7 McGregor A R, Watson A, Yunis E, et al. Familial clustering of scleroderma spectrum disease. Am $\mathcal{f}$ Med 1988; 84 1023-32.

8 Gladman D D, Keystone E C, Baron M, Lee P, Cane D, Mervret $H$. Increased frequency of HLA-DR5 in scleroderma. Arthritis Rheum 1981; 24: 854-6.

9 Lynch C J, Singh G, Whiteside T L, Rodnan G P, Medsger T A Jr, Rabin B S. Histocompatibility antigens in systemic T A Jr, Rabin B S. Histocompatibility antigens in systemic 314-8.

10 Whiteside T L, Medsger T A Jr, Rodnan G P. HLA-DR antigens in progressive systemic sclerosis (scleroderma) f Rheumatol 1983; 10: 128-31.

11 Black C M, Welsh K I, Maddison P J, Jayson M I V Bernstein R M. HLA antigens, autoantibodies and clinical subsets in scleroderma. Brf Rheumatol 1984; 23; 267-71.

12 Alarcon G S, Phillips R M, Warner C K, Acton R T, Barger B O. DR antigens in systemic sclerosis: lack of Barger B O. DR antigens in systemic sclerosis: lack
clinical correlations. Tissue Antigens 1985; 26: 156-8.

13 Livingston J Z, Scott T E, Wigley F M, et al. Systemic sclerosis (scleroderma): clinical, genetic and serological subsets. F Rheumatol 1987; 14: 512-8.

14 Barnett A J, Tait B D, Barnett M A, Toh B H. T lymphocyte subset abnormalities and HLA antigens in scleroderma (systemic sclerosis). Clin Exp Immunol 1989; 76: 24-29.

15 Erasmus L D. Scleroderma in gold miners in the Witswaterrand with particular reference to pulmonary manifestations. South African fournal of Laboratory and Clinical Medicine 1957; 3: 209-31.

16 Rodnan G P, Benedek T G, Medsger T A Jr, Cammata $\mathrm{R} J$. The association of progressive systemic sclerosis (scleroderma) with coal miners' pneumoconiosis and other forms of silicosis. Ann Intern Med 1967; 66: 323-34. 
17 Haustein U F, Ziegler V, Herrmann K. Silica induced scleroderma. F Am Acad Dermatol 1990; 22: 444-8.

18 Kumagai Y, Shiokawa Y, Medsger T A Jr, Rodnan G P. Clinical spectrum of connective tissue disease after cosmetic surgery. Observation of eighteen patients and review of the literature. Arthritis Rheum 1984; 27: 1-12

19 Wilson R H, McCormich W E, Tatum C F, Creech J L Occupational acro-osteolysis. Report of 31 cases. $\mathscr{f} A M A$

20 Walker A. Occupational acro-osteolysis (2 cases). Proceedings of the Royal Society of Medicine 1975; 68: 343-4

21 Maricq H R, Johnson M N, Whetstone C L, LeRoy E C. Capillary abnormalities in polyvinyl chloride workers. AAMA 1976; 236: 1368-71.

22 Owens G R, Medsger T A. Systemic sclerosis secondary to occupational exposure. Am f Med 1988; 85: 114-5.
23 Brassington R O, Thorpe-Swenson A J. Systemic sclerosis associated cutaneous exposure to solvents: case reports and review of the literature. Arthritis Rheum 1991; 34: 631-3.

24 Toxic Epidemic Study Group. Toxic epidemic syndrome, Spain, 1981. Lancet 1982; ii: 697-702.

25 Maddison P J, Skinner R P, Pereira R S, et al. Antinuclear antibodies in the relatives and spouses of nuclear antibodies in the relatives and spouses of patients

26 Barnett A J, Coventry D A. Scleroderma. 1. Clinical course of illness and response to treatment in 61 cases. Med $\mathcal{F}$ Aust 1969; 1: 992-1001.

27 Hooper B, Whittingham S, Mathews J D, Mackay I R, Curnow D H. Autoimmunity in a rural community. Clin Exp Immunol 1972; 12: 79-87.

站

吕

$\frac{0}{6}$

$\stackrel{20}{\Rightarrow}$

$\stackrel{\overrightarrow{0}}{9}$

흠

ब⿳亠口冋丁 